Цветков И.Б.

\title{
ПРАВОВОЕ РЕГУЛИРОВАНИЕ ВОЗБУЖДЕНИЯ УГОЛОВНОГО ДЕЛА ПО МАТЕРИАЛАМ ОПЕРАТИВНО-РОЗЫСКНОЙ ДЕЯТЕЛЬНОСТИ
}

\begin{abstract}
Аннотация: Предметом исследования является правовой режим возбуждения уголовного дела по материалам, полученным в ходе оперативно-розыскной деятельности. B статье проведён теоретико-правовой анализ положений действующего законодательства в сфрере уголовного процесса и оперативно-розыскной работы правоохранительных органов. Объектом исследования являются общественные отношения, возникающие в стадии возбуждения уголовного дела при проверке наличия основания для начала производства предварительного расследования по информации, полученной в результате производства оперативно-розыскных мероприятий. Особое внимание в исследовании уделено сущности такого повода для возбуждения уголовного дела, как рапорт должностного лица об обнаружении признаков преступления. В работе использован комплекс общенаучных и частно-научных методов познания, которые включают в себя такие методы, как нормативно-логический метод, системный метод, синтез, анализ, дедукция, индукция и другие методы научно-исследовательской деятельности. Новизна статьи заключается в разработке предложений по развитию фрорм и методов правового регулирования механизма возбуждения уголовного дела по материалам оперативно-розыскной деятельности. Основной вывод, который сделан по итогам исследования, состоит в следующем: процессуальные особенности возбуждения уголовного дела по результатам ОРД связаны с собиранием различных оперативно-служебных документов (рапортов, справок, актов, копий официальных документов, иных материалов, отражающих преступную деятельность проверяемых лиц, в том числе с применением научно-технических средств, и др.). Привлечённые к составлению этих документов граждане впоследствии могут быть допрошены в качестве свидетелей по уголовному делу. В результате будет значительно повышена степень достоверности собранной доказательственной инфоормации, а также гарантировано преобразование оперативных сведений в доказательства и их использование в уголовном судопроизводстве. Основным вкладом, который сделан автором в настоящей статье, это необходимость развития правового регулирования реализации сведений, полученных в ходе ОРД, в уголовном судопроизводстве.
\end{abstract}

Ключевые слова: Возбуждение уголовного дела, оперативно-розыскная деятельность, оперативно-розыскные мероприятия, повод, основание, признаки преступления, предварительное расследование, доследственная проверка, оперативное документирование, доказательственная информация.

Review: The research subject is the legal regime of initiation of a criminal case on the base of the materials of operational investigations. The paper analyzes the provisions of the existing criminal legislation and the legislation regulating operational investigations of law enforcement agencies. The research object is the range of social relations appearing on the stage of initiation of a criminal case when analyzing the reason for initiating a preliminary investigation on the base of the data acquired in the result of operational investigations. Special attention is paid to the concept of such a reason for initiation of a criminal case as a report of an official about the elements of crime. The author applies the set of general scientific and special methods of cognition including the normative-logical method, the system method, analysis, synthesis, deduction, induction and other research methods. The novelty of the study consists in the proposals about the development of forms and methods of legal regulation of the mechanism of initiation of a criminal case on the base of the materials of operational investigations. The author concludes that the procedural peculiarities of initiation of a criminal case on the base of operational investigation results are connected with collecting various operational documents (reports, certificates, acts, copies of official documents, and other materials reflecting criminal activity of the persons under 


\section{Полицейская деятельность 3 • 2016}

investigation) using scientific and technological instruments. The persons involved in these documents collecting can be later interrogated as the witnesses in a criminal case. It will increase the validity of the collected evidential base and guarantee the operational information transformation into evidences and their use in criminal proceedings. The author declares the necessity to develop legal regulation of use of the materials, collected during investigational operations, in criminal proceedings.

Keywords: Initiation of a criminal case, operational search activity, operational investigations, reason, ground, elements of crime, preliminary investigation, pre-investigation check, operative documenting, evidential base.

B диспозиции ч. 2 ст. 140 Уголовно-процессуального кодекса Российской Федерации (далее - УПК РФ) законодателем регламентировано положение, определяющее сущность одного из обязательных условий правомерного возбуждения уголовного дела. Таковым является наличие основания для его возбуждения, т.е. достаточных данных, указывающих на признаки преступления. В словаре русского языка понятие «достаточный» объясняется как удовлетворяющий потребностям, необходимым условиям; «основание» - как причина, достаточный повод, оправдывающий что-нибудь; «доказательство» - как довод или фракт, подтверждающий, доказывающий чтонибудь; «данные» - как сведения, необходимые для какого-нибудь вывода, решения [1].

Совокупность «достаточных данных», с одной стороны, определяет содержание основания для возбуждения уголовного дела, а с другой стороны, служит ориентиром при проведении доследственной проверки в целях устранения информационной неопределённости сообщения о состоявшемся или подготавливаемом общественно опасном деянии. При принятии решения о возбуждении уголовного дела соответствующее должностное лицо органа предварительного расследования должно опираться на обоснованные и достоверные сведения, указывающие на наличие преступления, по признакам которого данное дело возбуждается.

Названное процессуальное решение может быть принято уже только при наличии самих сведений о преступном событии; при этом не требуется, чтобы они обязательно в полной мере характеризовали противоправное деяние во всех его квалифицирующих признаках. Данное правило применяется даже в том случае, когда полученные данные, указывающие на наличие объекта и объективной стороны преступления, не исключают полностью дру- гих версий имевшего место события; это обстоятельство не служит препятствием началу производства по уголовному делу. Более того, необходимо отметить, что уголовно-процессуальный закон обязывает органы предварительного расследования возбудить уголовное дело по фракту совершения общественно опасного деяния, независимо от того, имеются какие-либо сведения в отношении лица, являющегося субъектом преступления, или нет.

Наличие достаточных данных, указывающих на признаки преступления, выявляется путём проведения доследственной проверки первичной информации, представленной в поступившем сообщении и рассматриваемым в качестве повода для возбуждения уголовного дела (ч. 1 ст. 140 УПК РФ). В свете рассматриваемых проблем принципиальное значение имеет тот фракт, что законодатель для характеристики основания возбуждения уголовного дела не использовал уголовно-правовой термин «состав преступления» а также уголовнопроцессуальное понятие «событие преступления» [2]. В этой связи необходимо отметить, что стадия возбуждения уголовного дела не призвана решать задачу, направленную на установление оснований для привлечения к уголовной ответственности конкретного физического лица за совершение определённого преступления. Если подобные выводы и будут здесь сформулированы, то в подавляющем большинстве случаев они носят вероятностный, предположительный характер, в рамках проверки одной из выдвинутых версий.

Заслуживает внимания позиция Пленума Верховного Суда РФ, который в п. 16 Постановления от 10 февраля 2009 г. № 1 прописал, что предметом проверки законности и обоснованности постановления о возбуждении уголовного дела в случае его обжалования в суд является наличие законных повода и основания принятия данного решения и соблюдения 
предусмотренного для этого порядка. Обстоятельства самого уголовного дела не должны оцениваться судом, рассматривающим такие жалобы, поскольку эти обстоятельства образуют предмет предварительного расследования и судебного разбирательства [3].

Согласно ч. 2 ст. 11 Федерального закона об оперативно-розыскной деятельности (далее - ФЗ об ОРД) результаты такой деятельности могут служить поводом и основанием для возбуждения уголовного дела. Сотрудники оперативных подразделений, будучи одновременно работниками органа дознания, обязаны принимать необходимые оперативно-розыскные меры в целях обнаружения признаков преступлений (в том числе подготавливаемых или совершаемых) и лиц, их совершивших; принимать заявления и сообщения о преступлениях, предотвращать и пресекать их на стадии приготовления либо покушения на них (ч. 1 ст. 144 УПК РФ). Кроме того при обнаружении (в том числе в результате производства оперативно-розыскных мероприятий) признаков преступлений указанные должностные лица правомочны возбудить уголовное дело и выполнить по нему неотложные следственные действия, а также производить оперативно-розыскные действия после передачи уголовного дела следователю, если не установлено лицо, совершившее это преступление (ч. 4 ст. 157 УПК РФ).

Для реализации этих компетенций законодатель наделил оперативные подразделения полномочиями сугубо инструментального характера, а именно правами относительно:

- проведения проверок финансово-хозяйственной деятельности предприятий, учреждений и организаций независимо от форм собственности, а также лиц, занимающихся индивидуальной предпринимательской и иной хозяйственной деятельностью;

- применения различных способов оперативного осмотра и наблюдения, в том числе сопряжённых с негласным проникновением в жилище и иные помещения, а также внедрением штатных негласных сотрудников в преступное сообщество;

- снятия информации с технических каналов связи, контроля почтовых отправлений, телеграфрных и иных сообщений, прослушивания телефонных переговоров;
- проведения проверочной закупки, а также контролируемой поставки товаров, предметов и веществ, в том числе запрещённых к обороту;

- создания и использования автоматизированных информационных систем (включая целевые системы профилактического назначения);

- внесения соответствующим государственным органам, общественным объединениям или должностным лицам, предприятиям, учреждениям и организациям обязательных для рассмотрения представлений об устранении причин и условий, способствовавших совершению преступлений, и т.д. [4].

Этот перечень дополняют меры, предусмотренные положениями уголовно-процессуального закона, регламентирующими возможность осуществления конкретных процессуальных (в том числе следственных) действий в ходе доследственной проверки сообщений о преступлении в порядке, установленном ч. 1 ст. 144 УПК РФ.

Осуществляя оперативно-розыскные мероприятия по выявлению сведений, необходимых для раскрытия и расследования преступлений, оперативные сотрудники одновременно должны принимать меры по их проверке, закреплению и оценке. В этой связи допускается заведение дел оперативного учёта, с помощью которых обеспечивается оперативно-розыскное документирование в целях собирания и систематизации указанных сведений, а также принятия на их основе соответствующих решений органами, осуществляющими ОРД (ч.ч. 1, 2 ст. 10 ФЗ об ОРД).

В силу изложенных обстоятельств между оперативным документированием и процессуальным доказыванием существует тесная взаимосвязь, которая обусловлена уже тем, что в соответствии с требованиями ФЗ об ОРД документирование должно быть направлено на обеспечение процесса доказывания. Так, например, согласно ст. 11 названного закона результаты ОРД могут быть использованы для подготовки и осуществления следственных и судебных действий, проведения оперативно-розыскных мероприятий по выявлению и установлению лиц, подготавливающих, совершающих или совершивших преступления, а также для розыска лиц, скрывшихся от орга- 


\section{Полицейская деятельность 3 • 2016}

нов дознания, следствия и суда, имущества, подлежащего конфискации.

Учитывая указанные обстоятельства, можно заключить, что при организации и осуществлении оперативного документирования особое внимание необходимо обратить на содержание его предмета и основные направления получения доказательственной информации, т.к. от этого в последующем будет зависеть возможность и успешность собирания и проверки конкретных видов доказательств по уголовному делу. Полагаем, что при определении предмета оперативного документирования и направлений поиска источников доказательственной информации целесообразно руководствоваться нормами уголовно-процессуального закона, регламентирующими перечень обстоятельств, подлежащих установлению при производстве по уголовному делу (ст. 73 УПК РФ), и виды доказательств в уголовном судопроизводстве (ст. 74 УПК РФ). Несоблюдение и игнорирование этого условия сделают процесс документирования беспредметным и предопределят получение отрицательного результата в части раскрытия преступления [5].

Оформление результатов производства ОРД может быть реализовано путём составления различных оперативно-служебных документов: рапортов, справок, актов, копий официальных документов, иных материалов, отражающих преступную деятельность проверяемых лиц, в том числе с применением научно-технических средств, и др. [6]. К составлению таких документов нередко привлекают граждан, которые впоследствии по уголовному делу могут выступить в качестве свидетелей. Это существенно повышает уровень достоверности получаемой доказательственной информации, облегчает преобразование оперативных сведений в доказательства и их трансформацию в уголовный процесс.

Инициатива по поводу реализации сведений, полученных в ходе ОРД, и возможности их использования при принятии решения о возбуждении уголовного дела принадлежит в первую очередь оперативному сотруднику. В этой связи он должен всесторонне проанализировать содержание оперативных материалов и оценить степень их полноты для использования в качестве основания для начала производства по уго- ловному делу. Представляется, что результаты ОРД должны содержать в себе убедительные и полноценные сведения следующего характера: где, когда, какие признаки и какого именно преступления были обнаружены, каковы обстоятельства его выявления, сведения о субъектах, его совершивших, и лицах, осведомлённых о преступлении, о местонахождении предметов, документов и иных объектов, обладающих признаками доказательств.

Успех в раскрытии и расследовании тяжких, замаскированных и совершённых в условиях неочевидности преступлений во многом предопределяется эффективностью оперативной работы и высокопрофессиональным документированием сведений, полученных в ходе ОРД. Признавая значимость этой деятельности, законодатель предусмотрел самостоятельную норму, регламентирующую такой повод для возбуждения уголовного дела, как рапорт должностного лица об обнаружении признаков преступления (ст. 143 УПК РФ). В ней прописано, что сообщение о совершённом или готовящемся преступлении, полученное из иных источников информации, чем указанные в ст. 141 «Заявление о преступлении» и ст. 142 «Явка с повинной» УПК РФ, принимается лицом, получившим данное сообщение, о чём составляется названный рапорт. В рассматриваемой ситуации иными источниками выступают результаты производства гласных и негласных оперативно-розыскных мероприятий [7].

Учитывая изложенные обстоятельства, можно заключить следующее. Процессуальные особенности возбуждения уголовного дела по результатам ОРД связаны с собиранием различных оперативно-служебных документов (рапортов, справок, актов, копий официальных документов, иных материалов, отражающих преступную деятельность проверяемых лиц, в том числе с применением научно-технических средств, и др.). Привлечённые к составлению этих документов граждане впоследствии могут быть допрошены в качестве свидетелей по уголовному делу. Тем самым будет значительно повышена степень достоверности собранной доказательственной информации, а также гарантировано преобразование оперативных сведений в доказательства и их использование в уголовном судопроизводстве. 


\section{Библиография:}

1. Ожегов С.И. Словарь русского языка. М.: Оникс, 2008. С. 158, 162.

2. Безлепкин Б.Т. Комментарий к Уголовно-процессуальному кодексу Российской Федерации (постатейный). 9-е изд., перераб. и доп. М.: КноРус, 2010. С. 186.

3. Постановление Пленума Верховного Суда РФ от 10.02.2009 № 1 «О практике рассмотрения судами жалоб в порядке ст. 125 Уголовно-процессуального кодекса Российской Федерации» // Бюллетень Верховного Суда РФ. 2009. № 4.

4. Ахмедов А.Г., Стрелин С.Е. Современные методологические проблемы оперативно-розыскного предупреждения преступлений // Вестник Калининградского юридич. института МВД России. 2008. № 1. C. $110-111$.

5. Маркушин А.Г. Уголовно-процессуальное использование результатов оперативно-розыскной деятельности // Вестник Нижегородского университета им. Н.И. Лобачевского. Серия: Право. 2003. № 2. C. 355.

6. Попов А.П. Непосредственное обнаружение признаков преступления как повод к возбуждению уголовного дела: Дис. ... канд. юрид. наук. Н. Новгород, 1999. С. 116.

7. Астафьев Ю.В. Значение оперативно-розыскной информации в установлении оснований уголовнопроцессуального доказывания // Вестник Воронежского государственного ун-та. Серия: Право. 2008. № 1. C. 274.

8. Винокуров Ю.Е., Глушков А.И. К вопросу о структуре прокурорского надзора как вида государственной деятельности // Административное и муниципальное право. 2012. № 1. С. 30-32.

9. Глушков А.И., Пугашова Г.Н. Проблемные вопросы прекращения уголовного преследования в отношении несовершеннолетних // Юридический мир. 2007. № 12. С. 65.

10. Глушков А.И. Обеспечение прав и законных интересов несовершеннолетних потерпевших в ходе уголовного судопроизводства // Российская юстиция. 2012. № 12. С. 51-53.

11. Глушков А.И. Реализация в уголовно-процессуальном доказывании результатов оперативно-розыскной деятельности // Вестник Московского университета МВД России. 2012. № 2. С. 67-69.

12. Глушков А.И., Плешаков А.М. О некоторых вопросах организации работы полиции по профилактике безнадзорности и правонарушений несовершеннолетних // Вестник Московского университета МВД России. 2011. № 9. С. 94-95.

13. Глушков А.И., Головко Н.В. Организация взаимодействия следователя по противодействию торговле детьми и использованию рабского труда // Административное и муниципальное право. 2011. № 12. C. 53-56.

14. Головко Н.В. Доказывание по уголовным делам о торговле несовершеннолетними: дис. ...канд. юрид. наук. М.: МПГУ. 2012. С. 45.

15. Головко Н.В. Основные черты криминалистической характеристики торговли несовершеннолетними и использования их рабского труда // Российский следователь. 2011. № 9. С. 2-5.

16. Головко Н.В. Поводы и основание для возбуждения уголовного дела о торговле несовершеннолетними и использовании их рабского труда // Российский следователь. 2011. № 13. С. 24-27.

17. Уголовный процесс: учебник для вузов / А.В. Гриненко. 2-е изд., перераб. и доп. М.: Норма, 2013. С. 78.

18. Григорьев В.Н. Начало уголовного производства: система сдержек и противовесов // Союз криминалистов и криминологов. 2013. № 2. С. 17-21.

\section{References (transliterated):}

1. Ozhegov S.I. Slovar' russkogo yazyka. M.: Oniks, 2008. S. 158, 162.

2. Bezlepkin B.T. Kommentarii k Ugolovno-protsessual'nomu kodeksu Rossiiskoi Federatsii (postateinyi). 9-e izd., pererab. i dop. M.: KnoRus, 2010. S. 186.

3. Akhmedov A.G., Strelin S.E. Sovremennye metodologicheskie problemy operativno-rozysknogo preduprezhdeniya prestuplenii // Vestnik Kaliningradskogo yuridich. instituta MVD Rossii. 2008. № 1. S. 110-111.

4. Markushin A.G. Ugolovno-protsessual'noe ispol'zovanie rezul'tatov operativno-rozysknoi deyatel'nosti // Vestnik Nizhegorodskogo universiteta im. N.I. Lobachevskogo. Seriya: Pravo. 2003. № 2. S. 355.

5. Popov A.P. Neposredstvennoe obnaruzhenie priznakov prestupleniya kak povod k vozbuzhdeniyu ugolovnogo dela: Dis. ... kand. yurid. nauk. N. Novgorod, 1999. S. 116. 
6. Astaf'evYu.V.Znachenie operativno-rozysknoi informatsii vustanovlenii osnovanii ugolovno-protsessual'nogo dokazyvaniya // Vestnik Voronezhskogo gosudarstvennogo un-ta. Seriya: Pravo. 2008. № 1. S. 274.

7. Vinokurov Yu.E., Glushkov A.I. K voprosu o strukture prokurorskogo nadzora kak vida gosudarstvennoi deyatel'nosti // Administrativnoe i munitsipal'noe pravo. 2012. № 1. S. 30-32.

8. Glushkov A.I., Pugashova G.N. Problemnye voprosy prekrashcheniya ugolovnogo presledovaniya v otnoshenii nesovershennoletnikh // Yuridicheskii mir. 2007. № 12. S. 65.

9. Glushkov A.I. Obespechenie prav i zakonnykh interesov nesovershennoletnikh poterpevshikh v khode ugolovnogo sudoproizvodstva // Rossiiskaya yustitsiya. 2012. № 12. S. 51-53.

10. Glushkov A.I. Realizatsiya v ugolovno-protsessual'nom dokazyvanii rezul'tatov operativno-rozysknoi deyatel'nosti // Vestnik Moskovskogo universiteta MVD Rossii. 2012. № 2. S. 67-69.

11. Glushkov A.I., Pleshakov A.M. O nekotorykh voprosakh organizatsii raboty politsii po profilaktike beznadzornosti i pravonarushenii nesovershennoletnikh // Vestnik Moskovskogo universiteta MVD Rossii. 2011. № 9. S. 94-95.

12. Glushkov A.I., Golovko N.V. Organizatsiya vzaimodeistviya sledovatelya po protivodeistviyu torgovle det'mi i ispol'zovaniyu rabskogo truda // Administrativnoe i munitsipal'noe pravo. 2011. № 12. S. 53-56.

13. Golovko N.V. Dokazyvanie po ugolovnym delam o torgovle nesovershennoletnimi: dis. ...kand. yurid. nauk. M.: MPGU. 2012. S. 45.

14. Golovko N.V. Osnovnye cherty kriminalisticheskoi kharakteristiki torgovli nesovershennoletnimi i ispol'zovaniya ikh rabskogo truda // Rossiiskii sledovatel'. 2011. № 9. S. 2-5.

15. Golovko N.V. Povody i osnovanie dlya vozbuzhdeniya ugolovnogo dela o torgovle nesovershennoletnimi i ispol'zovanii ikh rabskogo truda // Rossiiskii sledovatel'. 2011. № 13. S. 24-27.

16. Grigor'ev V.N. Nachalo ugolovnogo proizvodstva: sistema sderzhek i protivovesov // Soyuz kriminalistov i kriminologov. 2013. № 2. C. 17-21. 